\title{
Isolation, Characterization of Fiber and Its Reinforcement in Film Formation
}

\author{
Kanimozhi R, Vijayaram R, Gokul D
}

\begin{abstract}
The aim of this project is to segregate the fiber from agricultural waste in three distinct stages such as alkali treatment, bleaching process, acid hydrolysis. Agricultural wastes such as cassava bagasse, sorghum stalk, corn stalk were selected. Initially the raw materials were subjected to chemical processes like alkali treatment and bleaching process to remove lignin and hemi cellulose. The chemically purified cellulose was then subjected to acid hydrolysis for isolation of fiber. Characterization of FTIR result shows that hemicellulose and lignin was partially eliminated. TGA was carried to know the thermal properties of the sample. The film was formed by casting method using isolated fiber, maize starch, agar, Tween 80. The fibers were incorporated into the film and their properties such as tensile strength, moisture content and solubility were studied
\end{abstract}

Keywords : Fiber, lignin, hemicelluloses, film

\section{INTRODUCTION}

Biopolymers utilized as a part of films. They offer ecological advantages in view of their accessibility, biocompatibility, organic degradability, maintainability, low energy consumption, furthermore cellulose fibers act by expanding the mechanical properties as simpler procedure because of their non-rough nature. Production of biodegradable film using cellulose fiber from agricultural waste such as cassava bagasse, sorghum stalk, maize stalk. During film formation, plasticizer are normally added, to overcome films brittleness. Films were formed by starch are brittle and difficult to handle. Water permeability for plastizicer is low. Due to the addition of fibers the water permeability of starch based films was decreased. This behavior was due to the hydroscopicity of cellulose fiber. Simultaneous effect of water diffusivity in the polymeric matrix and the solubility based on the Water vapour permeability

\section{MATERIALS AND METHODS}

Cassava bagasse was collected from Sri Gopalakrishna Sago industries in Namagiripet (Namakkal distrinct). Sorghum stalk and Corn stalk also collected from Namagiripet (Namakkal distrinct).

Revised Manuscript Received on December 16, 2019.

* Correspondence Author

First Author Name*, Kanimozhi R/Chemical engineering department Kalasalingam Academy of Research and Education, Virudhunagar , India. Email: kanimozhi.ranga@gmail.com

Second Author Name, Vijayaram R/Chemical engineering department, Kalasalingam Academy of Research and Education, Virudhunagar , India. Email: rvijayaram@gmail.com

Third Author Name, Gokul D/Chemical engineering department Kalasalingam Academy of Research and Education , Virudhunagar , India. Email: gklche99@gmail.com

\section{A. Alkali Treatment}

The cellulose was purified by Alkali treatment. This treatment is used to remove the lignin and hemicellulose from cassava bagasse. Alkali solution(4 wt $\% \mathrm{KOH}$ ) was treated with cassava bagasse and this mixture performed at $80^{\circ} \mathrm{C}$ into round bottom flask for 1 hour. This mixture was washed and filtered by using distilled water for several times. This treatment was repeated for twice.

\section{B. Bleaching Process}

Bleaching process solution was prepared acetic acid, aqueous chlorite and distilled water at $70^{\circ} \mathrm{C}$ for $1 \mathrm{~h}$. This mixture was cool and filtered using distilled water. The process is repeated several times.

\section{Acid Hydrolysis}

After alkali process and bleaching, The solution was under centrifugation process before that solution was maintained at $60^{\circ} \mathrm{C}$ for an hour and $6.5 \mathrm{M}$ of sulphuric acid was added. This hydrolysis was washed several by distilled water.

\section{FILM FORMATION}

Solutions was prepared by different composition of fiber, maize starch, sorbitol, agar and Tween-80. Casting method was used to prepare the film. The starch and distilled water was mostly used to prepare film solution and then prepared solution was heated up to $80^{\circ} \mathrm{C}$. The prepared solution was performed at magnetic stirrer and transferred into glass plate .The Glass plate was placed in hot air oven at $70^{\circ} \mathrm{C}$ for $12 \mathrm{~h}$. exclusion of references, it should be less than $5 \%$.

\section{RESULTS AND DISCUSSION}

\section{A. FTIR Spectra of Cassava Bagasse}

FTIR spectroscopy is an non-destructive technique. This linkage shows the presence of raw fiber at the peak of 1627.6 $\mathrm{cm}-1$.The peak present at the range of $1200-1300 \mathrm{~cm}-1$ exhibit characteristic group of lignin which is corresponding to the aromatic skeletal vibration. 


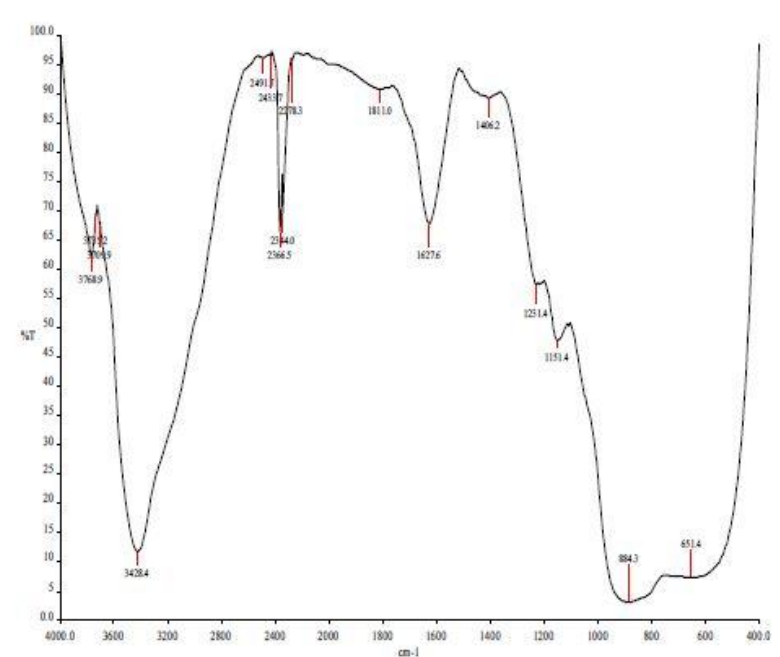

Fig. 1.FTIR Spectra of Cassava Bagasse

\section{B. FTIR Spectra of sorghum stalk}

The presence of cellulose can also be expected from the appearance of the signal at $896.0 \mathrm{~cm}-1$, which is typical structure of cellulose

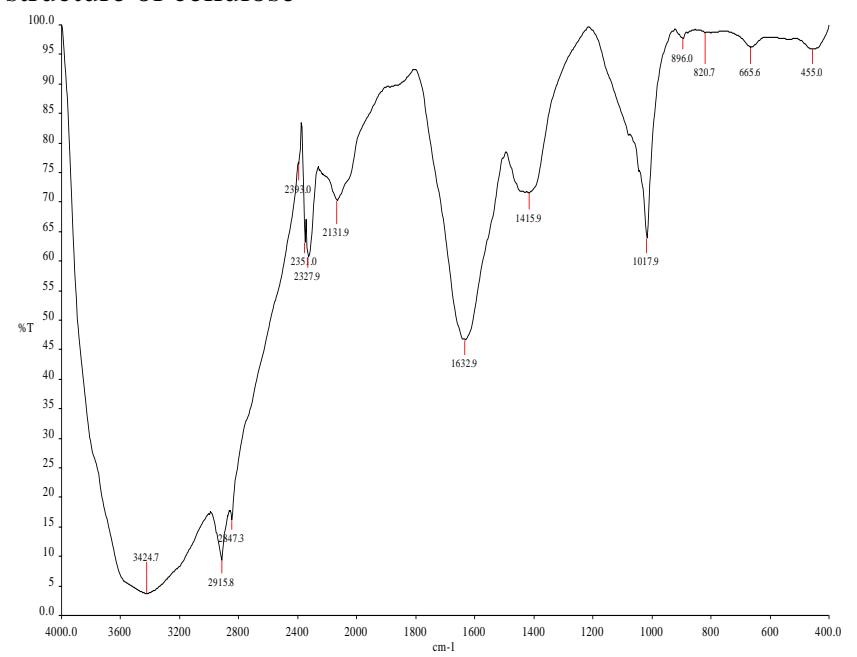

Fig. 2.FTIR Spectra of sorghum stalk

\section{FTIR Spectra of maize stalk}

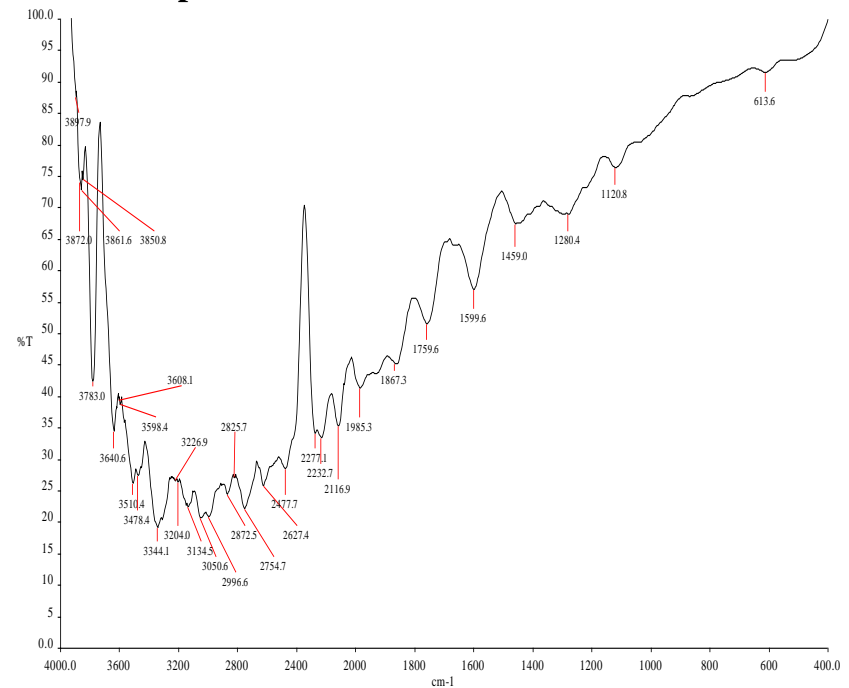

Fig. 3.FTIR Spectra of maize stalk

The presence of cellulose can also be expected from the appearance of the signal at $613.6 \mathrm{~cm}-1$

\section{TGA of Treated Cassava Bagasse}

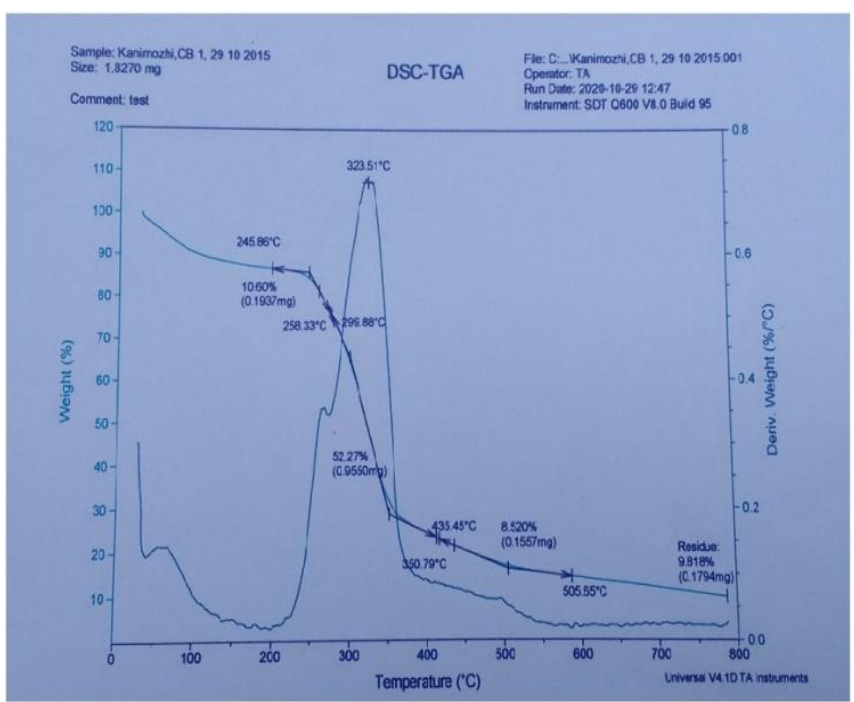

Fig. 4. Thermo gravimetric analysis of cassava bagasse

The thermal degradation of cassava bagasse sample was carried out using TGA in order to know the thermal properties. The below figure shows the normalized weight loss of the sample as a function of temperature. The degradation of cassava bagasse occurred between $245.86^{\circ} \mathrm{C}$ to $258.33^{\circ} \mathrm{C}$. First derivative peak temperature is $323.51^{\circ} \mathrm{C}$. The DSC decomposition peak is in exothermic pattern.

\section{E. TGA of Treated Sorghum Stalk}

The thermal degradation of sorghum stalk sample was performed by TGA to know the thermal properties. The degradation of sorghum stalk occurred between $285.87^{\circ} \mathrm{C}$ to $342.14^{\circ} \mathrm{C}$. First derivative peak temperature is $325.92^{\circ} \mathrm{C}$. The DSC decomposition peak is in exothermic pattern.

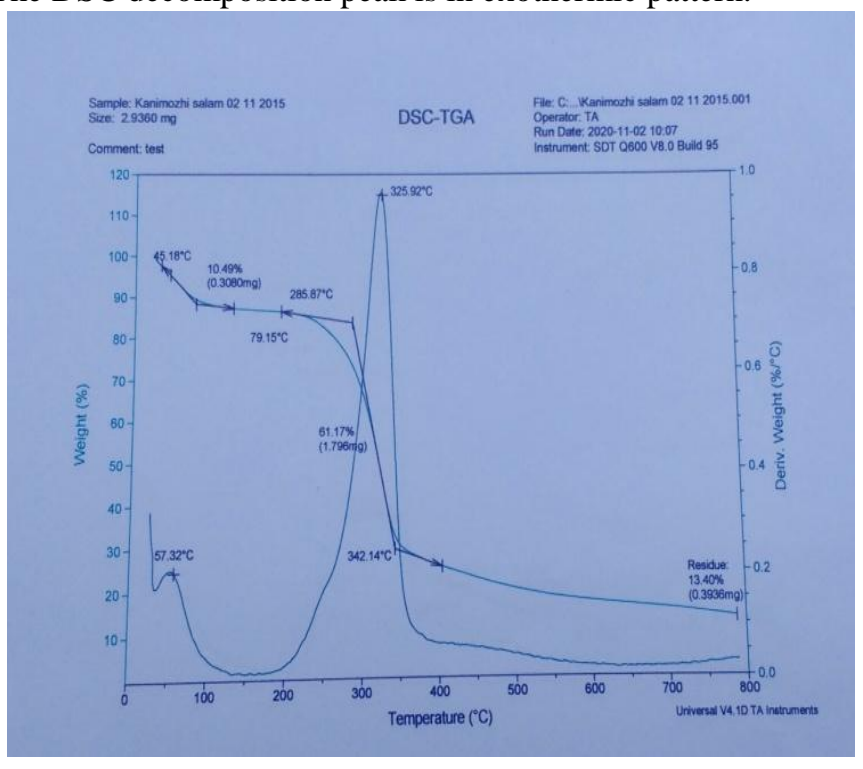

Fig. 5. Thermo gravimetric analysis of sorghum stalk

\section{F. TGA of Treated Maize Stalk}

The degradation of maize stalk sample was performed by TGA to know the thermal properties. The degradation of maize stalk occurred between $296.11^{\circ} \mathrm{C}$ to $351.30^{\circ} \mathrm{C}$. First derivative peak temperature is $335.56^{\circ} \mathrm{C}$. The $\mathrm{DSC}$ decomposition peak is in exothermic pattern. 


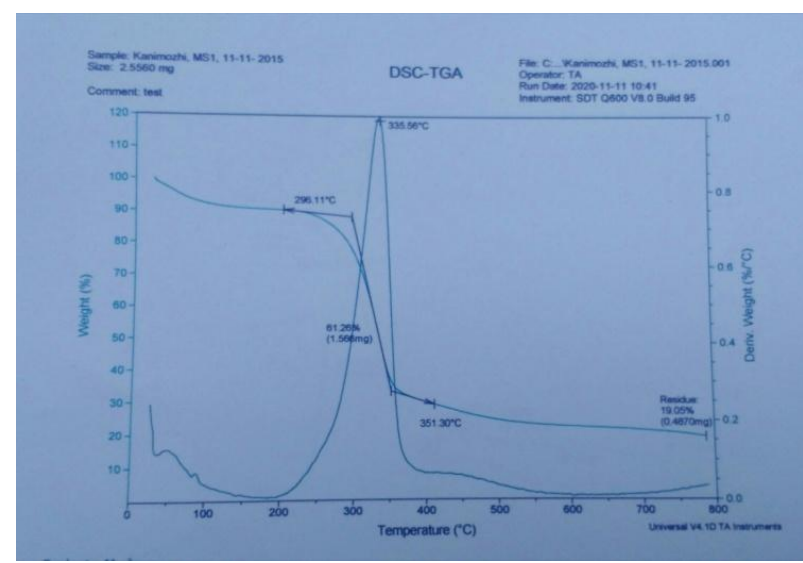

Fig. 6. Thermo gravimetric analysis of maize stalk

\section{G. XRD of Treated Cassava Bagasse}

Before and after chemical treatment .This fibers was under XRD test to study the crystalline structure of the fibers. The crystallinity index of before and after treatment of cassava bagasse was calculated and found to be $21.9 \%$ and $22.9 \%$. The result of his test show that increase in crystallinity

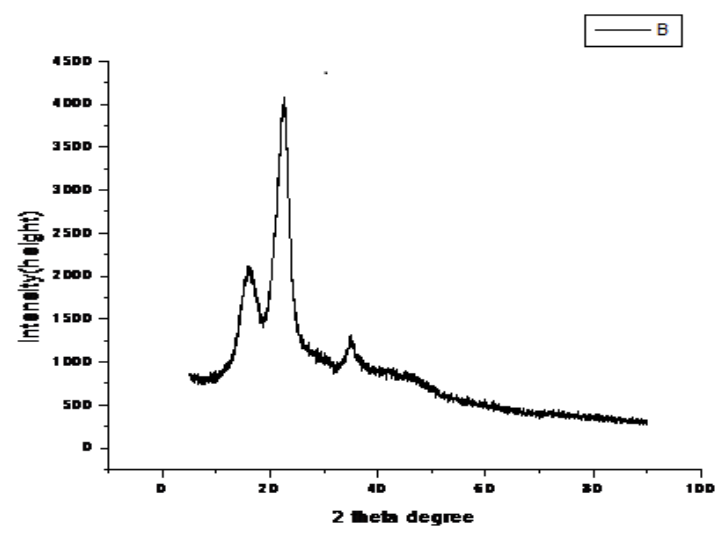

Fig. 7. XRD of Treated Cassava Bagasse

\section{H. XRD of Treated Maize Stalk}

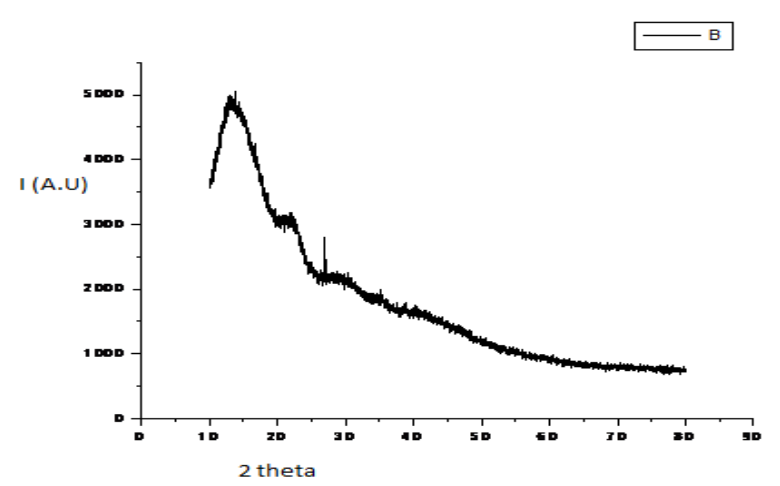

Nagendra Reddy (2005) reported that maize stalk fibers contain 52\% crystalline cellulose. Nagendra Reddy (2005) reported that fibers have an microfibrils fiber axis (MFA) of about $11^{\circ}$.The treated maize stalk fiber have an MFA of about $15^{\circ}$.A means the stronger fiber with lower elongation. I. Tensile Properties may vary with specimen thickness.Due to higher content of fibers, there is increase in the particle density which cause the more interaction between the fiber particles leads to the formation of aggregates.

\section{CONCLUSION}

Isolation of fibers from agricultural waste such as cassava bagasse, sorghum stalk, maize stalk by chemical treatment Thermo gravimetric analysis of cassava bagasse, sorghum stalk, maize stalk has first derivative peak temperature is $323.51^{\circ} \mathrm{C}, 325.92^{\circ} \mathrm{C}$ and $335.56^{\circ} \mathrm{C}$ respectively. $\mathrm{X}$ - ray diffractometer shows the increase in crystalline structure from $21.9 \%$ in cassava bagaase to $22.9 \%$, maize stalk fiber have an microfibril axis of about $15^{\circ}$. The film were obtained by casting method. It can be concluded that incorporation of cellulose fiber in film solution shows low moisture content, solubility in water and improves the tensile strength of films.

\section{REFERENCES}

1. A.C.souza ,R.Benze (2007) “ Influence of glycerol and clay nanoparticles content on tensile and barrier properties and glass transition temperature" Food science and technology vol.46: 110-117.

2. Benyahiaa, A. Merrouche (2013) "Study the effect of alkali treatment of natural fibers on the mechanical behavior of the composite unsaturated Polyester-fiber Alfa", Bordeaux, 26 - 30.

3. Abeer M. Adela, Zeinab H. Abd El-Wahabb, Atef A. Ibrahima, Mona T. Al-Shemya,(2009) "Characterization of microcrystalline cellulose prepared from lignocellulosic materials", Food Hydrocolloids vol: 23 pp.1328-1333

4. Alireza Kaboorani, Bernard Riedl (2015) "Surface modification of cellulose nanocrystals (CNC) by a cationic surfactant" Industrial Crops and Products 65 (2015) 45-55

5. Arup Mandal, Debabrata Chakrabarty (2011) "Isolation of nanocellulose from waste sugarcane bagasse (SCB) and its Characterization", Carbohydrate Polymers vol: $86 \quad$ (2011) pp.1291-1299

6. Bibin Mathew Cheriana, Alcides Lopes Leãoa, Sivoney Ferreira de Souzaa, Sabu Thomasb,Laly A. Pothanc, M. Kottaisamyd (2010) "Isolation of nanocellulose from pineapple leaf fibres by steam explosion”, Carbohydrate Polymers vol: 81 pp. 720-725

7. Diao Shea, Feng $\mathrm{Xu}$ (2010) "Physicochemical characterization of extracted lignin from sweet sorghum stem" Industrial Crops and Products, vol- 32 ,21-28

\section{AUTHORS PROFILE}

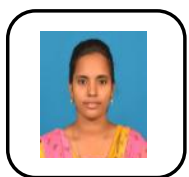

Kanimozhi $\mathbf{R}$ has completed B.Tech in Chemical Engineering and $\mathrm{M}$. Tech in chemical engineering. Published one paper in International Journal of Engineering Research and Development. Currently working as Assistant professor in department of Chemica Engineering in Kalasalingam Academy of Research and

education.

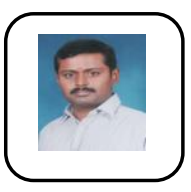

Vijayaram $\mathbf{R}$ has completed B.Tech and M. Tech in Chemical Engineering. Currently he is working as Assistant professor in Kalasalingam University. Earlier he worked in industries as Design and Estimation Engineer. His Area of interest is Heat transfer and Industrial safety. He has published research articles in various National and International journals. Also he has completed international certificate course in Safety Engineering from IOSH(UK), CPD(UK), KHDA etc.,

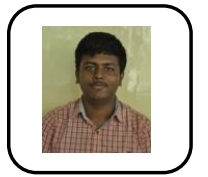

Gokul D currently pursuing Third year in Chemical Engineering of Kalasalingam Academy of Research and Education. He won first prize in Paper Presentation and Area of interest in waste water Treatment and Sonication. 